\title{
Parametric Analysis of Flow through Microchannels
}

\author{
Misba Jan ${ }^{1}$, Mohd Islam ${ }^{1}$, Asif Aslam² \\ ${ }^{1}$ Department of Mechanical Engineering, Jamia Millia Islamia, New Delhi (India) \\ ${ }^{2}$ Department of Mechanical Engineering, University of Kashmir, J\&K (India)
}

\begin{abstract}
This paper attempts to provide the extensive discussions based on the experimental work performed on a microchannel heat exchanger setup. The discussion begins with the description of the experimental setup and the requisite procedure which is followed by the results obtained during the course of work. The paper signifies the various conditions which somehow affect the flow and heat transfer characteristics in microchannels. The application of fluid flow in microchannels is used for thermal management in the various fields which include biotechnology, aerospace, mechatronics, and microelectronic devices. It is expected that the work provided in this paper will help the reader to analyse the practical design problems, where these results can be applied. Moreover, the information provided would be useful and of interest to the readers in this new domain.
\end{abstract}

Keywords: Microchannels, fluid flow characteristics, heat transfer rate, Reynolds number, pressure drop, friction factor, and Nusselt number.

\section{Introduction}

Nominally, microchannels can be defined as channels whose dimensions are less than 1 millimeter and greater than 1 micron. Above 1 millimeter the flow exhibits behaviour that is the same as most macroscopic flows. Currently, microchannels have characteristic dimensions anywhere from the submicron scale to hundreds of microns. Microchannels can be fabricated in many materials — glass, polymers, silicon, metals — using various processes including surface micromachining, bulk micromachining, moulding, embossing, and conventional machining with microcutters.

Microchannels offer advantages due to their high surface-tovolume ratio and their small volumes. The large surface-tovolume ratio leads to high rate of heat and mass transfer, making microdevices excellent tools for compact heat exchangers.

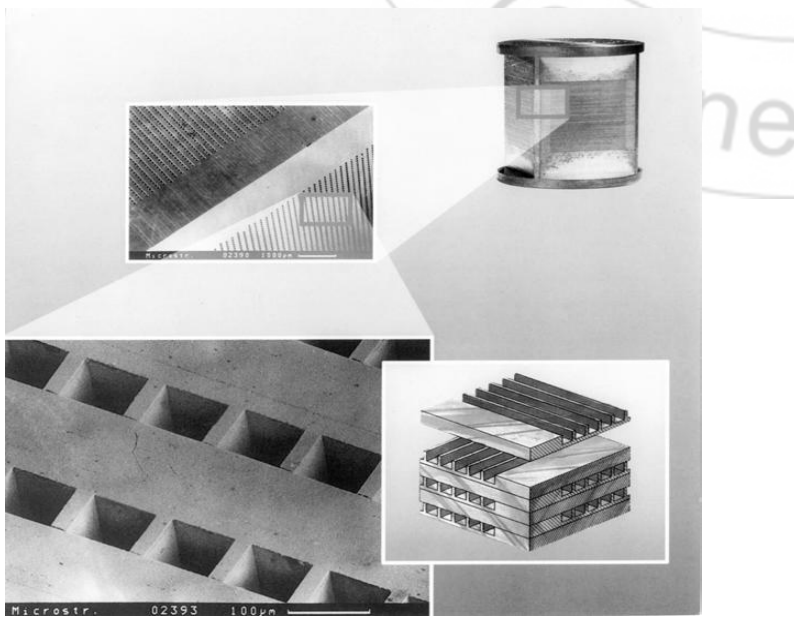

Figure 1: Micro heat exchanger constructed from rectangular channels machined in metal (From K. Schubert and D. Cacuci, Forschungszentrum, Karlsruhe.)

Though fluid flow and heat transfer in channels with very small hydraulic mean diameters have been of interest for quite some time, it has only been recently that the study of microscale thermal phenomena in engineering applications has gained relevance and importance. Focussed studies have been reported over a broad range of microscale thermal transport phenomena, and the depth and breadth of knowledge has increased dramatically. More recently, due to the significant potential of applications in micromachining, microelectronics, and microelectromechanical systems ( MEMS ), the field has expanded into the domain of nanoscale heat transfer.

There has been immense progress in the level of sophistication of the experimental techniques and theoretical analyses of microchannels over the past two decades. While earlier studies were conducted using conventional measurement techniques, probes and instrumentation, with the advent of MEMS-based technology, have facilitated the development of system- integrated measurement techniques. These have helped in revolutionizing the level of understanding, as well as serving to correct many of the inaccurate hypotheses associated with microscale heat transfer, most of which were the result of the limitations in measurement techniques as well as computational capabilities. Through improvements in these areas, there is now much more information available on the size limitations.

\section{Design of Microchannel Setup}

The base metal of microchannels is copper. The test section contains total of 79 circular microchannels each of $45 \mathrm{~mm}$ long and having the hydraulic diameter of $279 \mu \mathrm{m}$. The microchannels are arranged in circumferential manner on different Pitch Circle Diameters (PCD) in such a way that each microchannel contains more or less equal volume of water when the water passes through the test section. The outermost PCD contains 24 microchannels each $15^{\circ}$ apart; the fourth, third and second PCD contains 18 microchannels each $20^{\circ}$ apart and 1 microchannel at the centre of the baffle. Each PCD is $10 \mathrm{~mm}$ apart. The average surface roughness is about $5 \mu \mathrm{m}$. The whole system is connected to the oil bath in such a way that all the microchannels are dipped in the oil. 


\section{International Journal of Science and Research (IJSR) \\ ISSN (Online): 2319-7064}

Index Copernicus Value (2013): 6.14 | Impact Factor (2015): 6.391

Water is used as a working fluid. Water is pumped from the water holding tank by a high precision pump of $0.5 \mathrm{HP}$ having a specification of $240 \mathrm{~V}$ and $1500 \mathrm{rpm}$. In order to avoid blockage of the microchannels, submicron filter device of $0.1 \mu \mathrm{m}$ is installed between the outlet of pump and the inlet section of the test section. The volume flow rate of water flowing through the microchannels is measured by a collecting beaker. During measurement the regulator was used to set the desired pressure difference across the test section.

The microchannel heat exchanger is instrumented with thermocouples and pressure taps to monitor the fluid flow and heat transfer through the microchannels. 3 copper on the inlet and outlet positions of the test section as well as on the top portion of the oil bath to measure the temperature of water flowing through the microchannels and oil in the oil bath respectively. 1 rod type PT-100 thermocouple placed on the top portion of the oil bath which is connected to the BTC through heater. The thermocouples are calibrated by the standard comparison method. the accuracy of the temperature measurement is estimated to be $+0.3^{\circ} \mathrm{C}$. All the thermocouples are connected to DTI-301 9-point temperature indicator. This temperature indicator is calibrated and have an accuracy of $\pm 0.5 \%$. constantan button type PT-100 thermocouples are mounted

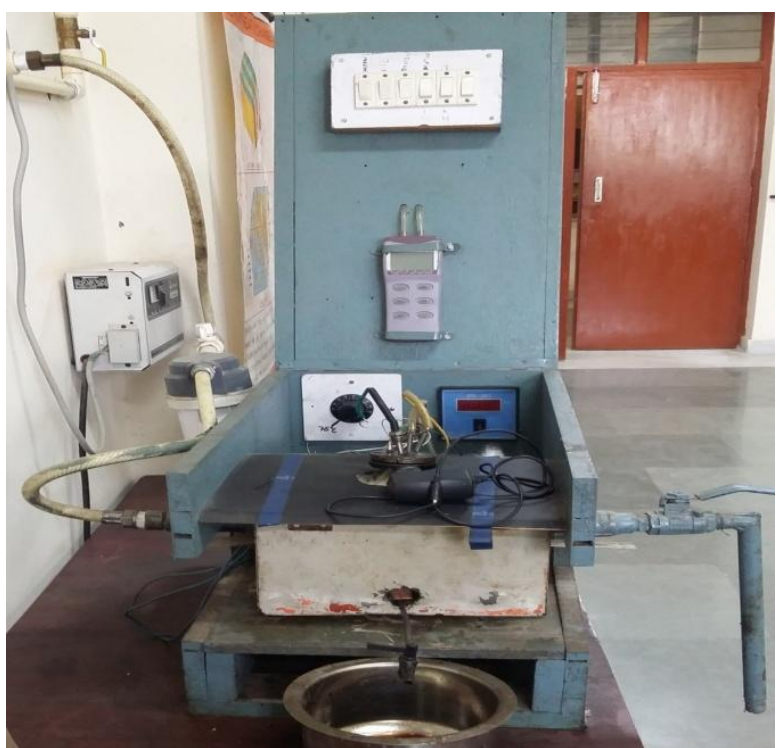

Figure 3: Side view of the setup

The collecting beaker is used to measure the water flow rate drained out from the test section. In this investigation $300 \mathrm{ml}$ of water is collected in each cycle and time of collection is recorded in order to find out the volumetric flow rate. The volumetric beaker used has a resolution of $2.5 \mathrm{ml}$ and the stopwatch used has a resolution of $0.01 \mathrm{~s}$.

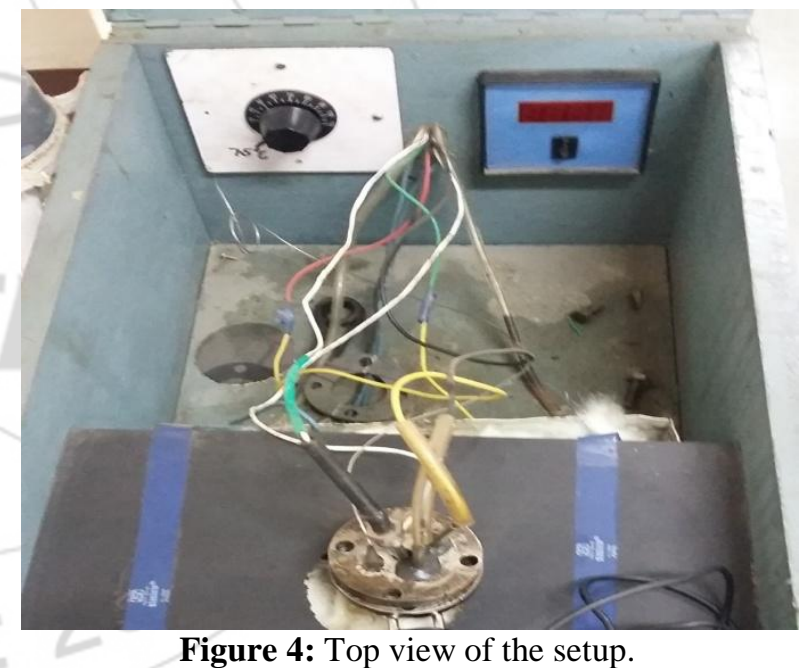

Figure 2: Front view of the setup.

The heater which was used to heat the oil in the oil bath is of $250 \mathrm{~W}$. The heater is connected through BTC (Blind Temperature Controller). BTC cuts the current supply of heater when the temperature of the oil in oil bath reaches the desired temperature.

To measure the pressure differential between the inlet and outlet position of the test section, a hand operated digital RS232 manometer is used. This battery-operated hand-held device has a pressure range of 0-100 Psi with an accuracy of $\pm 0.3 \%$ of its full scale at $25^{\circ} \mathrm{C}$ and gives the differential pressure of water in 5 different units.

\section{Basic Correlations}

The Reynolds number $R e$ is defined as:

$$
R e=\rho u_{m} D_{h} / \mu_{m}
$$

where $\mu_{m}$ and $\rho_{m}$ are mean dynamic viscosity and mean density of fluid at an arithmetic mean temperature $\left(T_{\mathrm{m}}=\right.$ $\left.\left(T_{\mathrm{o}}+T_{\mathrm{i}}\right) / 2\right)$, respectively. It should be noted that the fluid properties are functions of the temperature and values are obtained from correlations for dynamic viscosity $(\mu)$ correlations for dynamic viscosity $(\mu)$, thermal conductivity $(k)$, specific heat $\left(c_{p}\right)$, and density $(\rho)$ of DI water.

For incompressible flow through horizontal channels of constant cross-sectional area, $f_{\mathrm{c}}$ can be calculated by

$$
f_{c}=2 \tau_{w} / \rho_{m} u_{m}{ }^{2}=D_{h} \Delta P / 2 \rho_{m} u_{m}{ }^{2} L(2)
$$

where $\tau_{w}$ is the wall shear stress, $L$ is the channel length, and $u_{m}$ is the mean flow velocity. 


\section{International Journal of Science and Research (IJSR) \\ ISSN (Online): 2319-7064}

Index Copernicus Value (2013): 6.14 | Impact Factor (2015): 6.391

Results for the total heat transfer rate and the axial distribution of the mean temperature are derived as follows for the constant surface temperature condition. Defining $\Delta T$ as $T_{\mathrm{s}}-T_{\mathrm{m}}$, the equation may be expressed as

$$
d T_{m} / d x=-d(\Delta T) / d x=\left(P_{w} / m c_{p}\right) h \Delta T(3)
$$

From the definition of the average convection heat transfer coefficient, it follows that

$$
\begin{aligned}
\ln \left(\Delta T_{o} / \Delta T_{i}\right) & =-\left(P_{w} L / m c_{p}\right) h_{L} \\
=-\left(A_{s} / m c_{p}\right) h_{L}, T_{s} & =\text { constant }
\end{aligned}
$$

where $h_{L}$, or simply $h$, is the average value of $h$ for the entire channel, $A_{s}$ is the heat exchange area between the working fluid and wall surface inside the channel. Rearranging,

$$
\begin{array}{r}
\Delta T_{o} / \Delta T_{i}=T_{s}-T_{m, o} / T_{s}-T_{m, i} \\
=\exp \left[\left(-A_{s} / m c_{p}\right) h\right], T_{s}=\text { constant }
\end{array}
$$

For a general form of Eq. (5), one can obtain

$$
\begin{gathered}
T_{s}-T_{m}(x) / T_{s}-T_{m, i} \\
=\exp \left[\left(-P_{w} x / m c_{p}\right) h\right], T_{s}=\text { constant }(6)
\end{gathered}
$$

Since, by definition, Nusselt number equals to $h \cdot \mathrm{D}_{\mathrm{h}} / \lambda$, the average value of $\mathrm{Nu}$ for the entire channel can be expressed as

$$
\begin{gathered}
N u=\left(-D_{h} / \lambda_{m}\right) \ln \left(\Delta T_{o} / \Delta T_{i}\right) m c_{p} / A_{s}, \\
T_{s}=\text { constant }
\end{gathered}
$$

where $\lambda_{m}$ and $c_{p}$ are the mean thermal conductivity and heat capacity at constant pressure of DI water at an arithmetic mean temperature, respectively; $A_{s}$ is the heat exchange areas between the walls and fluid. For the heat exchange at the constant heat flux, the deduction of correlations can be found in [1]. Moreover, Lee et al. [2] examined the validity of conventional correlations and numerical analysis approaches in predicting the heat transfer behaviour in microchannels for correctly matched inlet and boundary conditions.

\section{Assumptions}

- In order to investigate the fluid flow and heat transfer characteristics of heat exchanger, the water through the microchannels is allowed to flow under constant temperature condition. As it is very difficult to get accurate readings of wall temperatures along the microchannels in heat exchanger. Thus, a constant temperature hot oil bath is used to impose a constant surface boundary condition on the walls of the microchannels.

- For each measurement, the flow is considered to have reached a steady state when the readings of the temperatures and the pressure drop do not change anymore. at such a state, the temperatures, the pressure drop and the flow rate are monitored and recorded for about 15 mins.

\section{Experimental Methodology}

The first step is to fill the water holding tank with water. Once the water is filled, the water holding tank is properly covered. After this, fill the oil bath with oil and close it properly. Then turn on the heater and wait until the temperature of the oil in the oil bath reaches the desired temperature. Once the desired temperature is attained, open the valve of water holding tank and start the motor. This allows the water to flow through the test section. a proper flow rate is obtained with the help of valve by monitoring the digital manometer and set the valve at a position where a predetermined pressure is measured on the manometer. Once the desired pressure is obtained, wait for 15-20 minutes so that the flow attains a steady state. After this note down the reading of temperature of water at the inlet and outlet positions of the test section as well as the temperature of the oil from the temperature indicator. Also note down the reading of differential pressure of water through the test section from a digital manometer. Once the temperature and pressure measurement is done, start collecting the predetermined amount of water from the exit section in the collecting beaker and note down the time of collection. The procedure is repeated several times for different differential pressure readings.

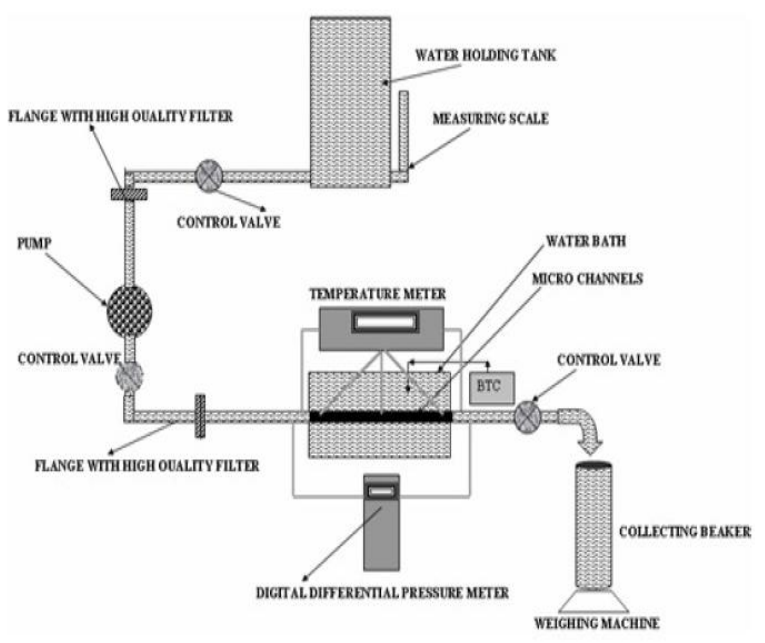

Fig. 5 Schematic arrangement of the experimental setup

\section{Results And Discussion}

Figure 6 shows a graph in non-dimensional form which relates friction factor and Reynolds number. It depicts that in the range of $500<\operatorname{Re}<1000$, the flow exhibits developing laminar flow. Moreover, it indicates that in the range of $1000<\operatorname{Re}<2000$, flow is in the transition region. This early transition in the microchannels tested here is due to the inlet conditions and hydrodynamic entrance length. [6] 


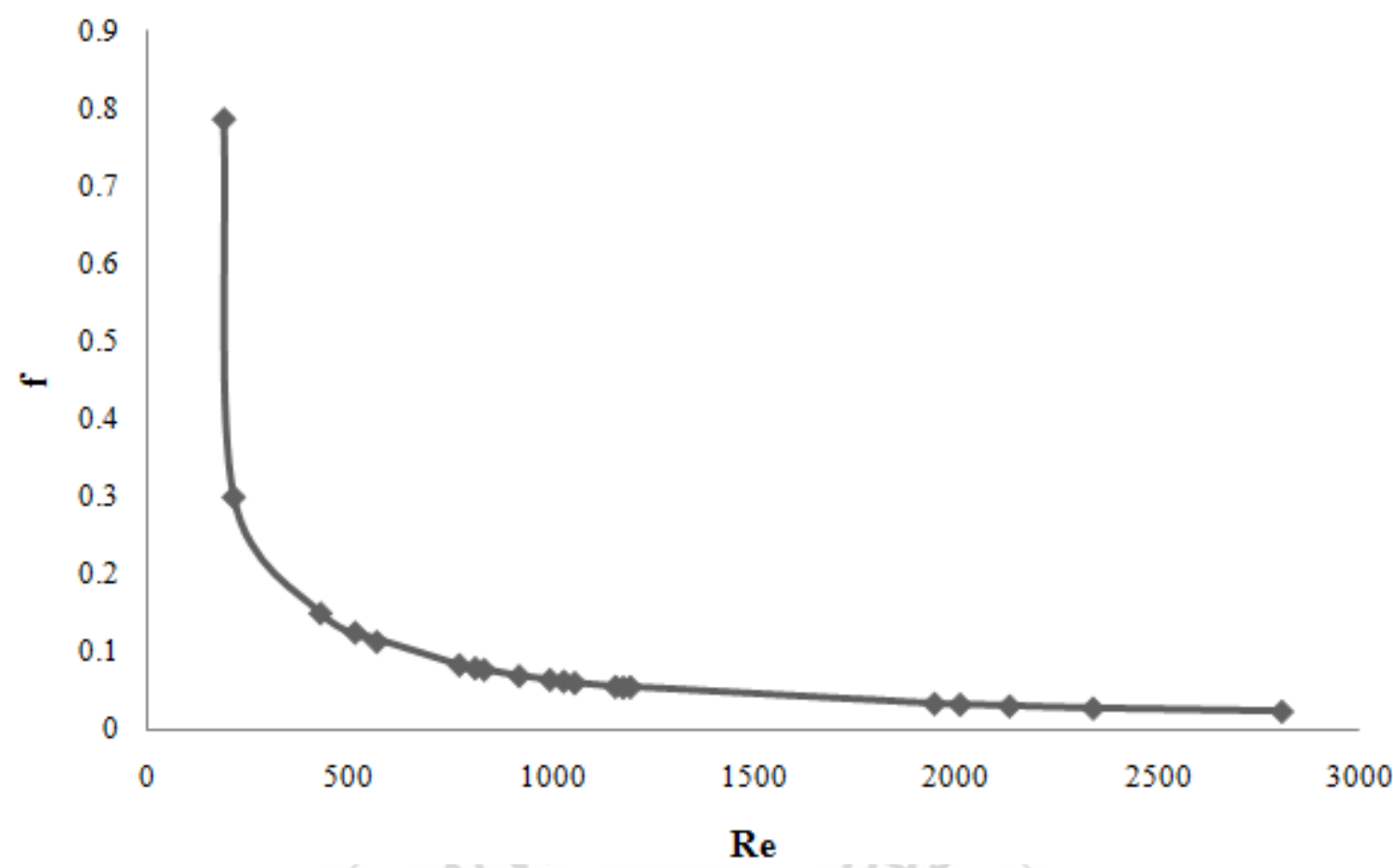

Figure 6: Experimental plot of $f$ versus $R e$ in microchannel flow.

Figure 7 shows a graph in which the pressure drop is plotted against Reynolds number. It is clear that there is an increase in pressure drop with an increase in Reynolds number. This graph depicts minor deviation from the conventional theory which is largely due to the surface roughness and it has been assumed that the given setup has an average surface roughness of $5 \mu \mathrm{m}$. However, it has been stated that the surface roughness plays a predominant role on pressure drop of laminar liquid flow in microchannels [4]. Various researchers have emphasized that the surface roughness is a major cause of deviations between experimental results and theoretical correlations. [22]

It must be noted that the pressure drop measured between the inlet and outlet of microchannels cannot be assumed to be a fully developed pressure drop because of the losses incurred. Therefore, the entrance and exit conditions are also responsible for discrepancies in the results. [13]

Another factor that could cause experimental errors is the channel geometry. It is difficult to etch or machine the exact channel dimension, thus the width of a microchannel may vary over the length and this could determine erroneous data. [15]

For the sake of accuracy, it has been computed that the percentage error in results due to the surface roughness is about $35 \%$ which is judged to be in fair agreement. 


\section{International Journal of Science and Research (IJSR) \\ ISSN (Online): 2319-7064}

Index Copernicus Value (2013): 6.14 | Impact Factor (2015): 6.391

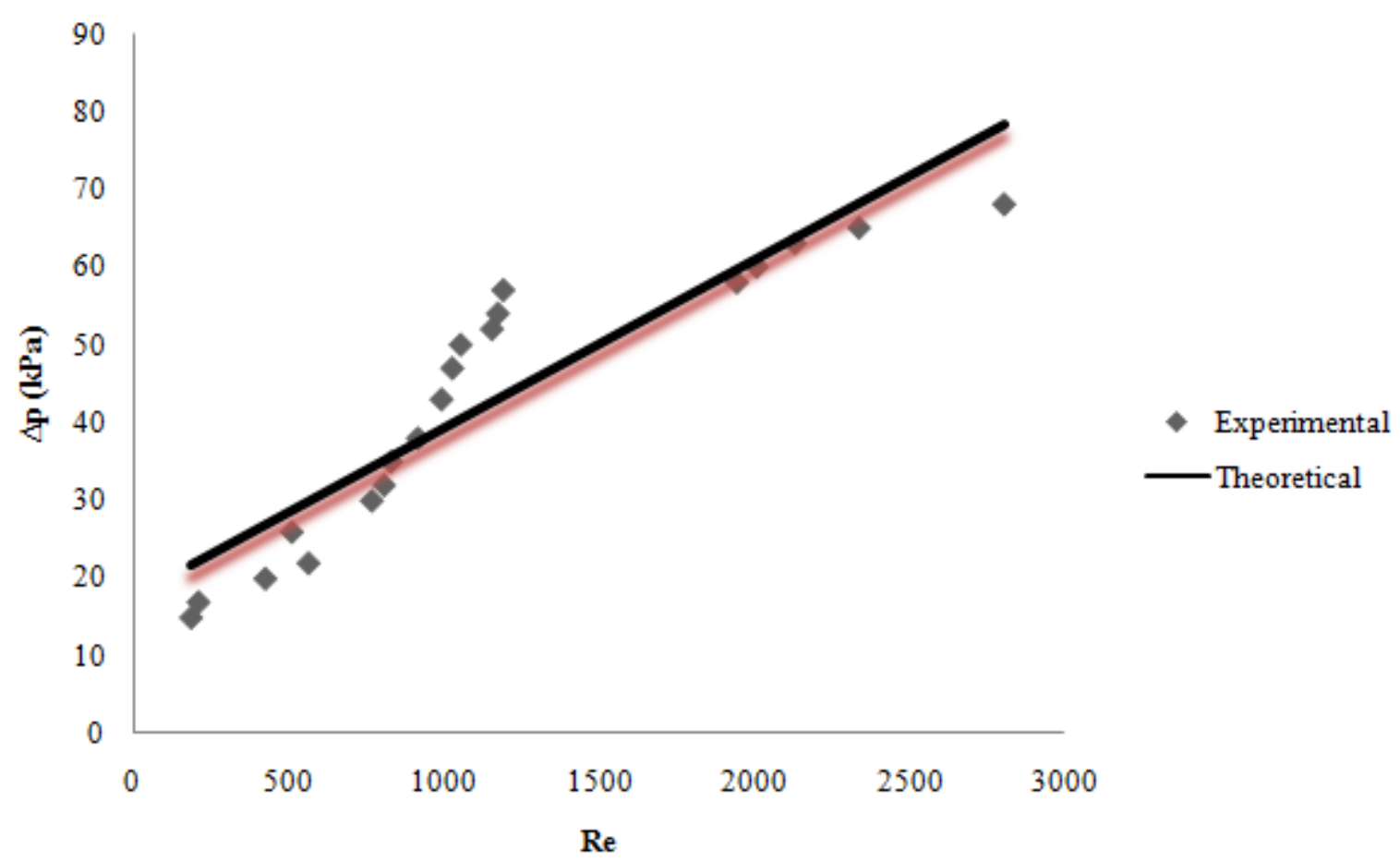

Figure 7: Graph showing the pressure drop plotted against Reynolds number

Figure 8 shows a graph in non-dimensional form between Nusselt number and Reynolds number. The graph reveals that the magnitude of Nusselt number increases as the Reynolds number becomes larger. A very important factor to be notified in this analysis is that the flow field is thermally developing. However, the influence of the entrance region should be markedly more significant in the laminar regime than in the turbulent regime since the thermal entrance length in the turbulent regime is much smaller than in the laminar regime. Certain deviations have been reported in this graph as compared to the macroscale theory. It should be noted that the roughness-viscosity effect plays a significant role to cause such deviations [5]. However, it can be clearly analyzed that the deviations for high Reynolds number are significantly higher than those for lower range. Moreover, the most common source of error that is not taken into consideration is axial conduction. Mostly, the experimental setups have three-dimensional heat conduction but it is generally assumed that the one-dimensional conduction is experienced in the test section which leads to erroneous results [23]. Another issue, which has not been highlighted much, is the effect of viscous heating. With the relatively large pressure drops for small flow rates, a large amount of kinetic energy is converted into heat and this variation in temperature affects the liquid properties along the channel length which causes considerable variations in the results. [24]

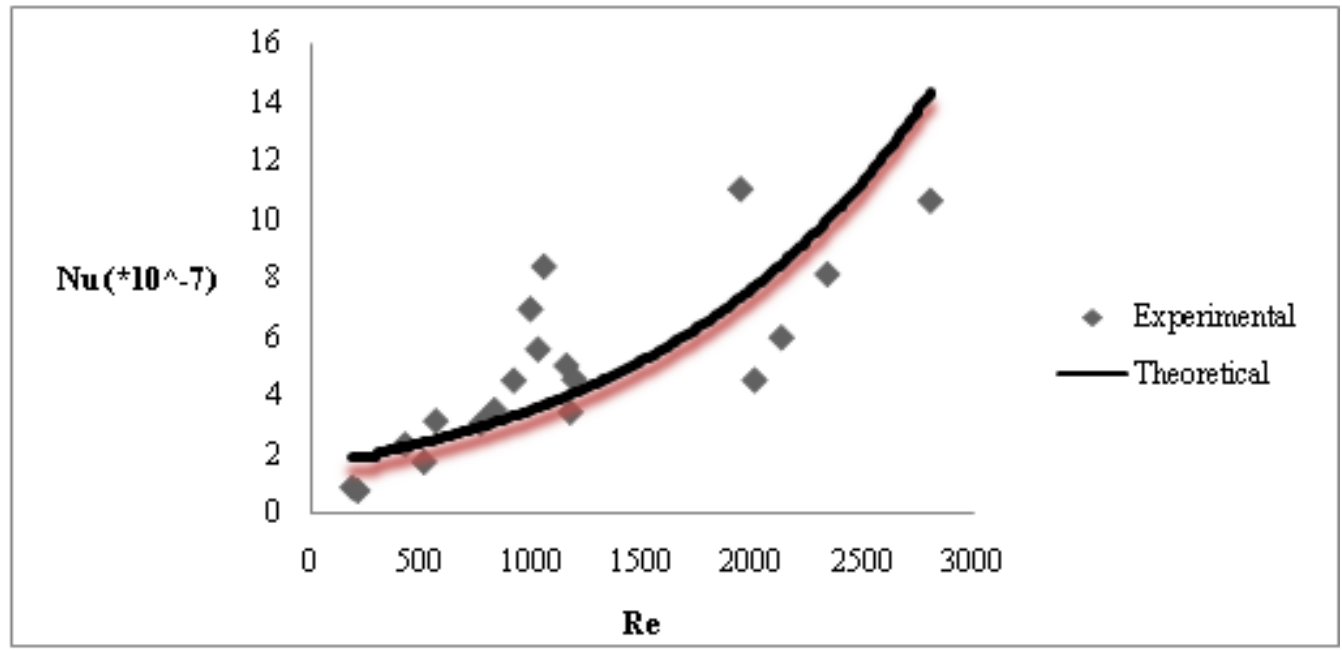

Figure 8: Variation of the Nusselt number as a function of the Reynolds number.

\section{References}

[1] Frank P. Incropera, David P. Dewitt, Fundamentals of Heat and Mass Transfer, Third edition, Wiley, 1990.
[2] Pho-Seng Lee, Suresh V. Garimella, and Dong Liu, "Investigation of heat transfer in rectangular microchannels," International Journal of Heat and Mass Transfer 48: 1688-1704, 2005. 


\section{International Journal of Science and Research (IJSR) \\ ISSN (Online): 2319-7064}

Index Copernicus Value (2013): 6.14 | Impact Factor (2015): 6.391

[3] Tuckerman, D.B. and R.F.W. Pease, High performance heat sinking for VLSI, IEEE Electron Device Letters, 1981.

[4] Yu, D., R. Warringto, R. Barron, and T. Ameel, An experimental and theoretical investigation of fluid flow and heat transfer in microtubes, Proceedings of the ASME/JSME Thermal Engineering Conference 1: 523530, 1995

[5] Lee, G.B., Lin, C.H., and Chang, G.L., "Micro Flow Cytometers with Buried SU-8/SOG Optical Waveguides," Sensors and Actuators A 103: 165-70, 2003.

[6] A. Bucci, G. P. Celata, M. Cumo, E. Serra, and G. Zummo, "Water single-phase fluid flow and heat transfer in capillary tubes," Paper No. ICMM20042406, Second International Conference on Microchannels and Minichannels, Rochester, NY USA: 221-228, June 17-19, 2004.

[7] Garimella, S., Condensation flow mechanisms in microchannels: Basis for pressure drop and heat transfer models, Heat transfer engineering 25: 104116, 2004.

[8] Peng, X.F. and B.X. Wang, Forced convection and flow boiling heat transfer for liquid flowing through microchannels, International Journal of Heat and Mass Transfer 36:3421-3427, 1993.

[9] Choi, S.B., R.F. Barron, and R.O., Warrington, Fluid flow and heat transfer in microtubes, Micromechanical Sensors, Actuators and Systems ASME DSC 32: 123134, 1991.

[10] Peterson, G.P., Analysis of a heat pipe thermal switch, Proceedings of the $6^{\text {th }}$ International Heat Pipe Conference, Grenoble, France: 177-183, 1987.

[11] Peng, X.F., Peterson, G.P., and Wang, B.X., "Frictional Flow Characteristics of Water Flowing through Rectangular Microchannels," Exp. Heat Transfer 7: 249-64, 1994.

[12] Pfahler, J., Harley, J., Bau, H., and Zemel, J., "Liquid Transport in Micron and Submicron Channels," Sensors and Actuators A21-A23: 431-34, 1990.

[13] White, F.M., Viscous Fluid Flow, 2nd ed., McGrawHill Series in Mechanical Engineering, eds. J.P. Holman and J.R. Lloyd,McGraw-Hill, New York, 1991.

[14] Wu, P. and Little, W.A., "Measurement of Friction Factors for the Flow of Gases in Very Fine Channels Used for Microminiature Joule-Thomson Refrigerators," Cryogenics 23: 273-77, 1983.

[15] Liu, D. and Garimella, S.V., "Investigation of Liquid Flow in Microchannels," J. Thermophys. Heat Transfer 18: 65-72, 2004.

[16] Judy, J., Maynes, D., and Webb, B.W. 2002. Characterization of frictional pressure drop for liquid flows through microchannels. International Journal of Heat and Mass Transfer 45(17):3477-3489.

[17] Sharp, K.V., and Adrian, R.J. 2004. Transition from laminar to turbulent flow in liquid filled microtubes, Experiments in Fluids 36:741-747.

[18] Lee, P.S., Garimella, S.V., and Liu, D. 2005. Investigation of heat transfer in rectangular microchannels, International Journal of Heat and Mass Transfer 48:1688-1704.
[19] Adams, T.M., Abdel-Khalik, S.I., Jeter, S.M., and Qureshi, Z.H. 1998. An experimental investigation of single-phase forced convection in microchannels. International Journal of Heat and Mass Transfer 41:851-857.

[20] Garimella, S.V. and C.B. Sobhan. 2003. Transport in microchannels-A critical review. Annual Review of Heat Transfer 13: 1-50.

[21] Mala, M., D.G. Li, and J.D. Dale. 1997. Heat transfer and fluid flow in microchannels. International Journal of Heat and Mass Transfer 40: 3079-3088.

[22] P.L. Young and S.G. Kandikar, "Surface roughness effects on Heat transfer in microchannels Single phase flow, A Critical Review", Proceeding of $6^{\text {th }}$ Int. ASME Conference on Nanochannels, Minichannels and Microchannels.

[23] Wynn Allen Phillips, Jr. "Experimental and numerical investigation of fluid flow and heat transfer in Microchannels" Thesis of Master of Science in Mechanical Engineering.

[24] J. Judy, D. Maynes and B.W. Webb, "Characterization of frictional pressure drop for liquid flows through icrochannels", Int. J. of Heat and Mass Transfer 45: 3477-3489, 2002 